\title{
Recurred Minor Salivary Gland Cancer in Base of Tongue, Endoscopic Neck Management
}

\author{
So Yeon Yoon, Gun Hyuk Lee, Kee Jae Song, Youn Jin Cho, and Hyun Jun Hong \\ Department of Otorhinolaryngology-Head and Neck Surgery, International St. Mary's Hospital, Catholic Kwandong University \\ College of Medicine, Incheon, Korea
}

\author{
설근부 소타액선암의 재발성 림프절 전이에서의 내시경적 치료 \\ 윤소연 · 이건혁 · 송기재 · 조윤진 · 홍현준 \\ 가톨릭관동대학교 의과대학 국제성모병원 이비인후-두경부외과학교실
}

\author{
Received April 9, 2020 \\ Revised May 7, 2020 \\ Accepted May 11, 2020 \\ Address for correspondence \\ Hyun Jun Hong, MD, PhD \\ Department of Otorhinolaryngology- \\ Head \& Neck Surgery, \\ International St. Mary's Hospital, \\ Catholic Kwandong University \\ College of Medicine \\ 25 Simgok-ro 100gil, Seo-gu, \\ Incheon 22711, Korea \\ Tel $+82-32-290-3878$ \\ Fax $+82-32-290-3879$ \\ E-mail hyunjun.hong@gmail.com
}

A 45-year-old female who presented with a salivary gland tumor on the oral and base of the tongue underwent surgery via intraoral approach. It led to a recurrence of the primary site and metastasis to bilateral cervical lymph nodes within 5 years of surgery. We performed resection of the recurred tumor via transoral approach and endoscope assisted neck dissection via retroauricular approach. The patient has been alive for 5 years without recurrence or any complications. We report on this case where a minimally invasive approach was used to obtain excellent cosmetic results and outstanding surgical outcomes.

Korean J Otorhinolaryngol-Head Neck Surg 2021;64(3):192-6

Key Words Endoscopic surgical procedure · Lymph node metastasis ·

Malignant epithelial tumor · Minimally invasive surgical procedure ·

Minor salivary gland · Salivary gland cancer.

\section{Introduction}

Minor salivary glands are spread out all areas of the oral submucosa including the hard palate except for anterior portion, soft palate, lip, buccal area and even tongue. Although minor salivary gland origin cancers account for a few percentages in head and neck area, malignant rates are higher than major one. Among low-grade malignant tumors of salivary gland, epithelial-myoepithelial carcinoma (EMC) is uncommon that accounts for only about up to $1 \%$ and usually wide excision of the tumor is treatment of choice.

Herein, we present a case of EMC of oral tongue with recurrent neck metastasis treated with intraoral approach and endo-

This is an Open Access article distributed under the terms of the Creative Commons Attribution Non-Commercial License (https://creativecommons.org/licenses/by-nc/4.0) which permits unrestricted non-commercial use, distribution, and reproduction in any medium, provided the original work is properly cited. scope assisted neck surgery via retroauricular (RA) approach which produced excellent cosmetic results.

\section{Case}

A 45-year-old female visited another hospital with a single oral and base of tongue mass for 10 years. She didn't have any symptoms, so she had not visited any hospital for 10 years. However, as the mass gradually increased, she had difficulty to articulate and swallow for several months. She had no medical disease history excepting probable systemic lupus erythematosus.

On the physical examination, about a $5 \mathrm{~cm}$ hard, fixed and fungating mass was palpable on the right oral and base of tongue area. Tongue was mobile, but there was a slight limitation of movement (Fig. 1A). The vocal cord movement was intact under laryngoscopy exam. There was no palpable lymph node 
on both neck areas.

$\mathrm{CT}$ and MRI showed a $6 \times 5 \mathrm{~cm}$ of tumorous mass on the base of tongue. The heterogeneous mass which has intermediate and low signal intensity in T1 weighted MRI was well bordered but extended to extrinsic muscle of tongue (Fig. 1B and C). Diagnostic biopsy was proven to malignant myoepithelial neoplasm. Minor salivary gland carcinoma of oropharynx (cT3N0M0, stage III) was clinically diagnosed.

A tumor, which sized $5.6 \times 4.8 \mathrm{~cm}$ was completely resected via a transoral approach under general anesthesia (Fig. 2A-C). The rubbery and well encapsulated mass was found, and it had a cystic portion (Fig. 2D). On the histopathologic examina- tion, myoepithelial cell proliferation with inconspicuous epithelial components was found. The tumor was very close to circumferential margin but there was no involvement of circumferential margin. After the surgery, the patient underwent combined chemotherapy and radiation therapy (CCRT) with $6000 \mathrm{cGy} / 30 \mathrm{fxs}$. The postoperative one year follow up physical examination and CT showed no evidence of malignancy. Tongue mobility and function of swallowing were preserved after surgery and postoperative CCRT. The process so far had been conducted at other hospitals, and she was follow up loss for 5 years.

Postoperative 5-years after the 1st surgery, the patient came
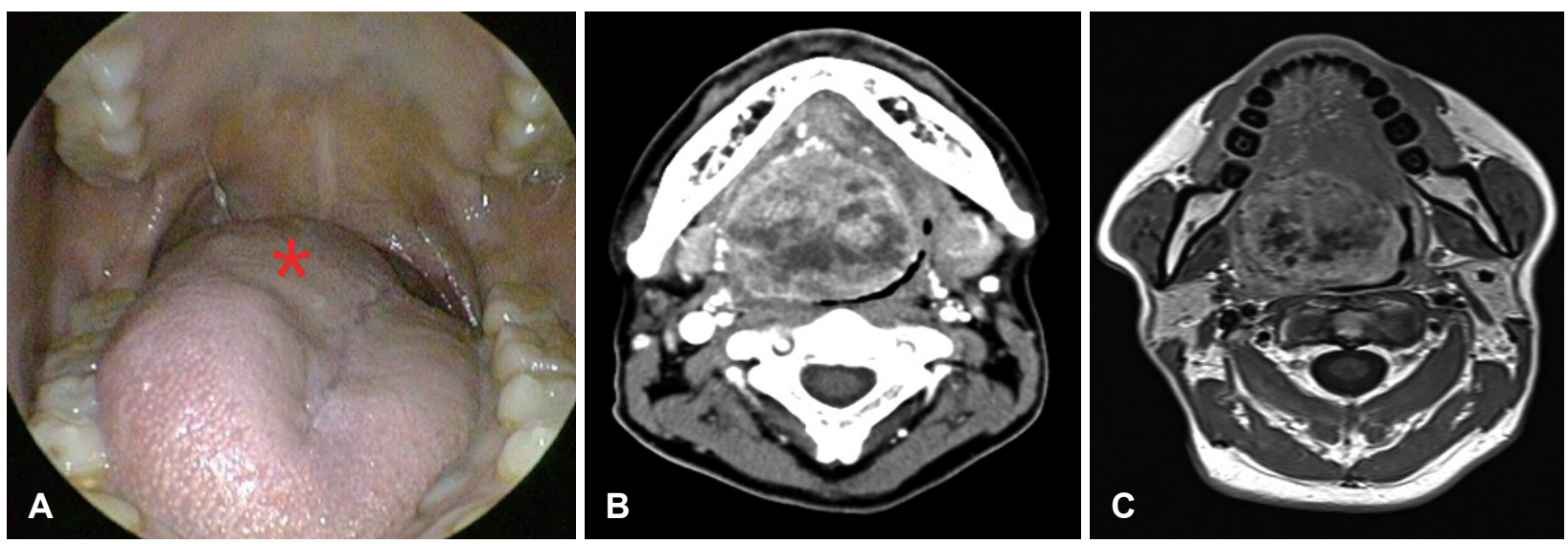

Fig. 1. First pre operation. A fixed and fungating mass was palpable on the right base of tongue (asterisk) (A). CT and MRI showed that about $6 \times 5 \mathrm{~cm}$ of heterogeneous-featured mass on the base of tongue was well encapsulated and extended to the extrinsic muscle of tongue. The mass has intermediate and low signal intensity in T1 weighted MRI $(B, C)$.
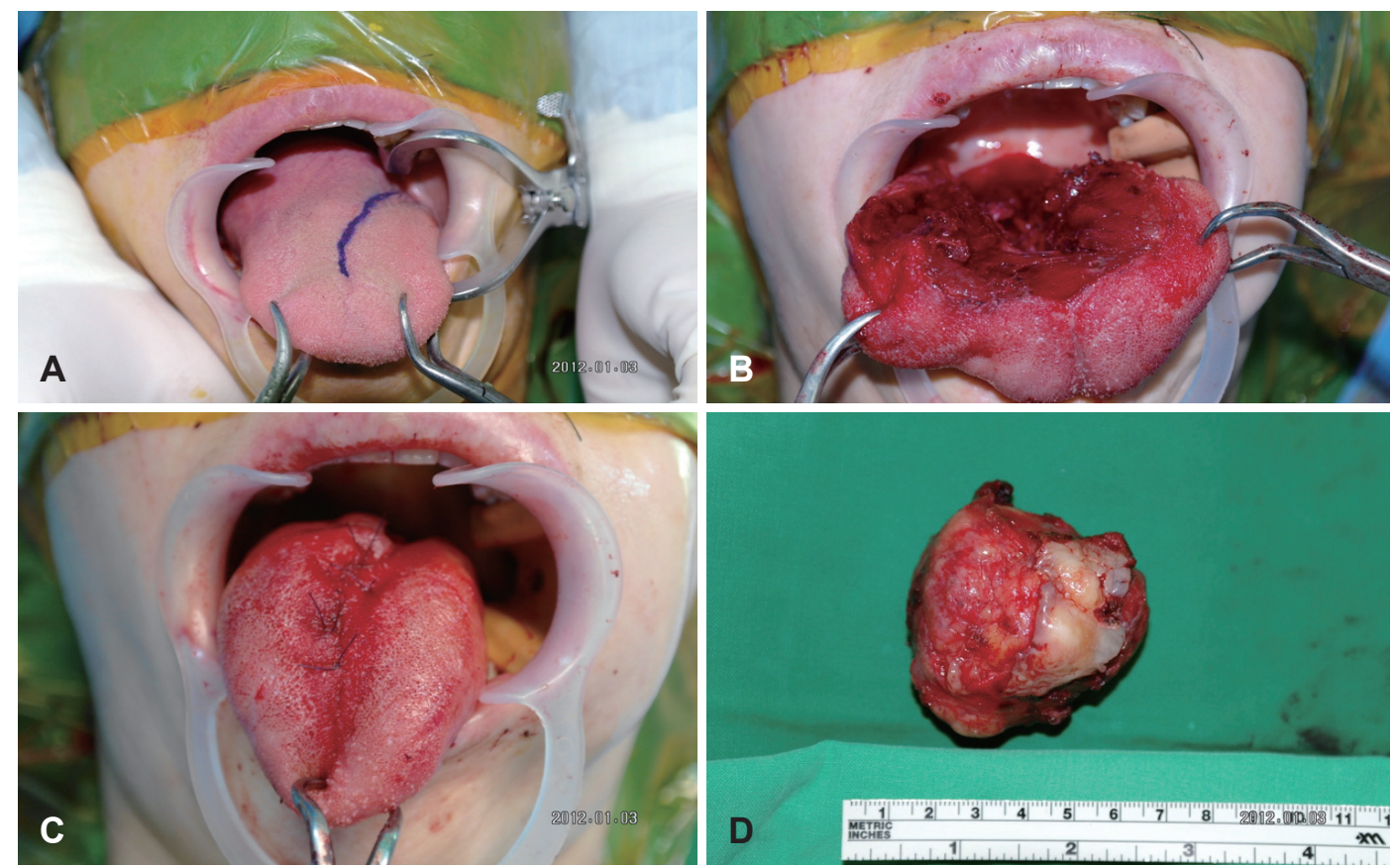

Fig. 2. First operation. The tumor was completely resected via a transoral approach under general anesthesia (A-C). Gross specimen. The rubbery and well encapsulated mass which sized $5.6 \times 4.8 \mathrm{~cm}$ had a cystic portion (D). 
to our department with oral pain. On the physical examination, a small hard and fixed mass was palpable on the right base of tongue (Fig. 3A and B). On the level II and III of both sides of neck, several moderately hard and non-tender masses were palpable approximately $2 \mathrm{~cm}$ in size.

T1 weighted contrast enhanced MRI showed an about 1-2 $\mathrm{cm}$ sized, elongated, solid and heterogenous lesion with pe- ripheral rim enhancement at the right base of tongue. It was extended to genioglossus muscle and several enlarged heterogenous lymph nodes at both neck level II and left level III (Fig. 3C-E).

The pathologic diagnosis by punch biopsy of base of tongue mass and core needle biopsy of neck lymph nodes was a malignant myoepithelial neoplasm, favor EMC with multiple lymph


Fig. 3. Second pre operation. A hard and fixed mass was palpable on the right base of tongue (asterisk) (A, B). T1 weighted contrast enhanced MRI showed an about $1-2 \mathrm{~cm}$ sized elongated solid heterogenous lesion with peripheral rim enhancement at right base of tongue to genioglossus muscle and several enlarged heterogenous lymph nodes at both neck level II and left level III (arrow) (C-E). Gross specimen. The rubbery and gray-white color of mass was well encapsulated $(F)$. 
node metastases. The EMC is same as previous biopsy results 5 years ago. A PET-CT showed a high-fluorodeoxyglucose (FDG) uptake lesion of tongue base and both enlarged neck nodes without distant metastasis. Minor salivary gland cancer of oropharynx (rcT1N2cM0, stage IVA) was diagnosed. The tumor was totally resected via transoral approach with 5 $\mathrm{mm}$ of margin. The rubbery and gray-white color of mass was well encapsulated (Fig. 3F). Adjacent soft tissues were free of tumor. Modified radical neck dissection was performed via a bilateral RA approach to the bilateral metastatic cervical lymphadenopathy. Finally, the pathologic diagnosis was an EMC of oropharynx with multiple neck metastases (4/13, 2 of right level III, 1 of left level IIa, 1 of left level III). The largest metastatic tumor size was $16 \mathrm{~mm}$ with $4 \mathrm{~mm}$ of extra nodal extension. The patient is undergoing observation without adjuvant treatment.

After the surgery, the patient was followed-up for 5 years. Up to now, there are no local recurrence or metastatic lesion (Fig. 4).

\section{Discussion}

In the mucosa of the oral cavity and nasopharynx, three major and countless minor salivary glands are spread out. The major salivary glands consist of parotid, submandibular, and sub- lingual glands, and tumors occur in this order, followed by the minor salivary glands. ${ }^{1)}$ Salivary gland cancer accounts for only approximately $5 \%$ of all head and neck cancers. ${ }^{2)}$ And the frequency of malignancy depends on the tumor location. ${ }^{2)}$ Spiro, ${ }^{3)}$ in 2807 salivary neoplasms, a malignant rate was reviewed that $82 \%$ occurred in minor salivary glands, $43 \%$ in submandibular glands, and $25 \%$ in parotid glands. Salivary gland cancers mostly appear as a painless or incidental mass, but some of the patients may present rapid growing mass, pain, enlarged neck nodes, and progressive loss of nerve function. ${ }^{4}$

There are about 450 to 700 minor salivary glands in oral cavity, oropharynx, nasal cavity, nasopharynx and larynx. About $50 \%$ of intraoral minor salivary gland tumors are malignant. ${ }^{5)}$ The malignant rate of them is different according to occurrence site. The common areas include hard and soft palate, lip and buccal mucosa. Patients complain various and symptoms and show signs depending on size and location of tumor. More than half of them are located in oral so usually cause a painless swelling and mass. Nasopharynx or nasal cavity origin tumors can cause nasal obstruction, epistaxis or facial pain. If the larynx is infiltrated by tumor, voice change or dyspnea can be happened. ${ }^{6)}$

EMC have both tubular and ductal structures lined by outer basal myoepithelial cells and inner luminal epithelial cells histologically. ${ }^{7,8)} 75 \%$ of EMC occur from the parotid gland,
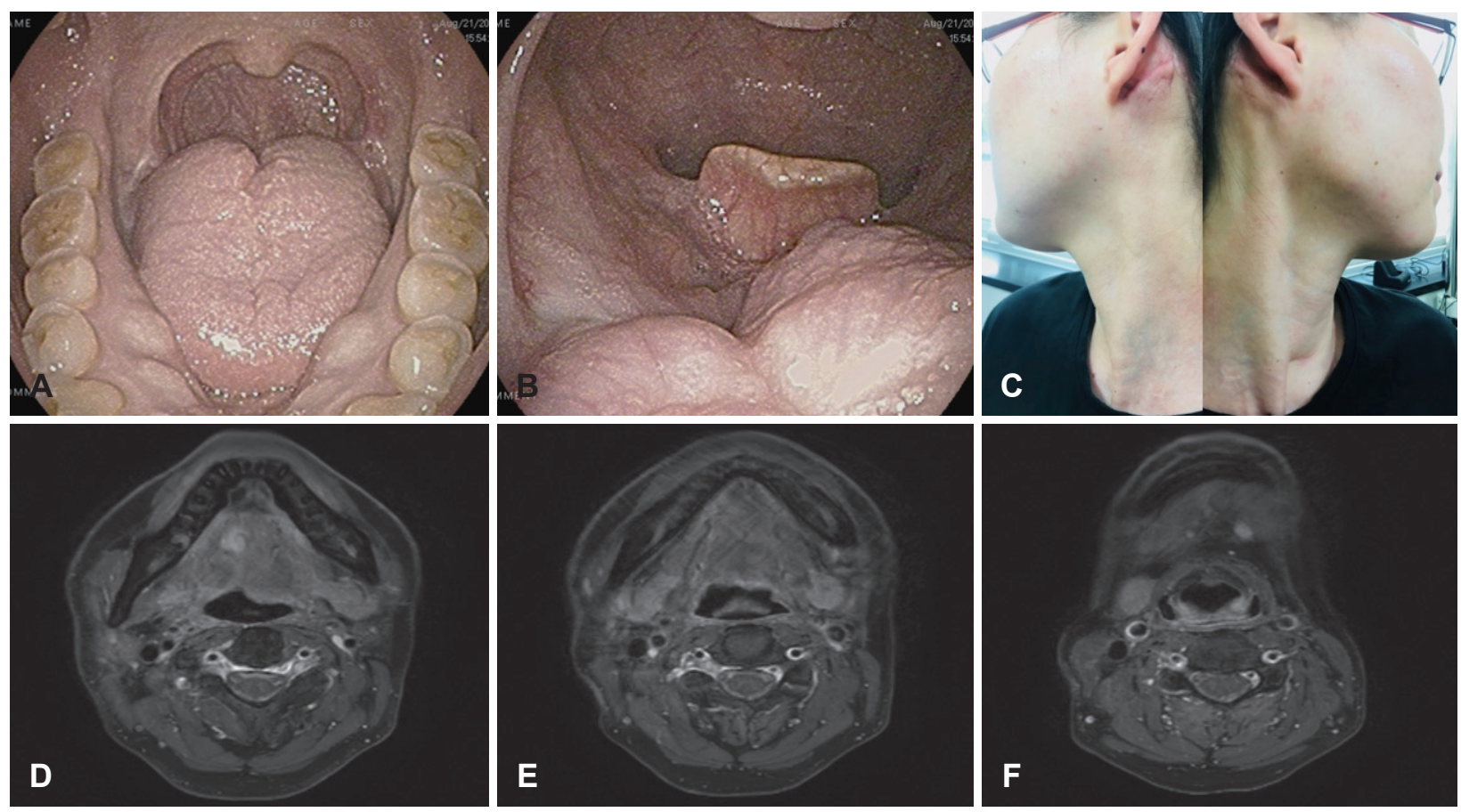

Fig. 4. 5 years after the surgery, there is no evidence of local recurrence or distant metastasis. The oral cavity and oropharynx after the removal $(A, B)$, both neck (C), and T1 weighted MRI (D-F). 
and approximately $10 \%$ arise in the submandibular glands and minor salivary glands respectively. ${ }^{7,8)}$ Especially the palate is the most prevalent site of the EMC. ${ }^{9)}$ EMC is generally a low grade malignant tumor of salivary glands and regional or distant metastasis is rare, but relatively has a high tendency for local recurrence." ${ }^{9)}$ The optimal treatment of EMC is not yet consented. In some studies, they argued that surgical resection with sufficient margins is considered the best treatment. And in some other studies, chemotherapy and radiotherapy may also be a selective option. ${ }^{10,11)}$

The ultimate goals of oral cancer treatment are to eradicate all cancer cells, preserve the function, minimize the complication, and prevent recurrence. The commonly used surgical approaches are transoral, lower or upper cheek flap, visor flap, pull through, lingual release and with or without mandibulotomy. ${ }^{12)}$ Of these methods, the peroral approach can be applied to early stage like $\mathrm{T} 1$ or 2 of oral cavity cancer of the mobile tongue, floor of the mouth, buccal mucosa, and upper or lower gingiva. And it enables surgical resection with enough margin simultaneously with primary repair and also leave minimal cosmetic and functional defects. ${ }^{13)}$

Presence of neck lymph node metastasis is one of the most important prognostic factors of head and neck cancer. Classic or modified radical neck dissection is a treatment of choice of nodal metastasis. Transcervical approach in conventional neck dissection leaves a prominent scar on the patient's neck. The need for improved cosmetic outcomes has become increasingly emphasized in head and neck surgery. ${ }^{14)}$ Modified facelift, RA, axillary, or transaxillary and RA approach can be used for endoscopically and robotically assisted neck dissection. ${ }^{14)}$

There are several benefits of endoscopic surgery via RA approach in comparison of conventional methods. ${ }^{15)}$ First, cosmetic effects are satisfactory. Along the hairline, the incision is hidden behind the neck therefore it cannot be seen easily although there is remnant postoperative scar. Second, the surgical procedures are minimally invasive to the patients, so they recover earlier. Patients therefore experienced less complaints like swelling and pain with rapid healing. Also, level II as well as level Ib and III can be seen better in an endoscopic approach. However, endoscopy provides limited direct visualization, so an operator may have difficulty in recognizing the surgical field precisely and managing intraoperative bleeding.

In our case, we did a successful removal of the primary site and neck metastases via transoral and RA approaches, the patient is being free from disease. Thus, we could obtain excellent results with the continually advancing surgical equipment and technique of head and neck surgery.

\section{Acknowledgments}

None.

\section{Author Contribution}

Conceptualization: Kee Jae Song. Investigation: Youn Jin Cho. Supervision: Hyun Jun Hong. Writing — original draft: So Yeon Yoon, Gun Hyuk Lee. Writing — review \& editing: So Yeon Yoon, Gun Hyuk Lee.

\section{ORCID}

Hyun Jun Hong

https://orcid.org/0000-0002-7808-7877

\section{REFERENCES}

1) Kumar V, Abbas AK, Aster JC. Robbins and cotran pathologic basis of disease. 9th ed. Philadelphia, PA: Elsevier Saunders;2015.

2) Boukheris H, Curtis RE, Land CE, Dores GM. Incidence of carcinoma of the major salivary glands according to the WHO classification, 1992 to 2006: A population-based study in the United States. Cancer Epidemiol Biomarkers Prev 2009;18(11):2899-906.

3) Spiro RH. Salivary neoplasms: Overview of a 35-year experience with 2,807 patients. Head Neck Surg 1986;8(3):177-84.

4) Stodulski D, Mikaszewski B, Stankiewicz C. Signs and symptoms of parotid gland carcinoma and their prognostic value. Int J Oral Maxillofac Surg 2012;41(7):801-6.

5) Waldron CA, el-Mofty SK, Gnepp DR. Tumors of the intraoral minor salivary glands: A demographic and histologic study of 426 cases. Oral Surg Oral Med Oral Pathol 1988;66(3):323-33.

6) Lopes MA, Kowalski LP, da Cunha Santos G, Paes de Almeida O. A clinicopathologic study of 196 intraoral minor salivary gland tumours. J Oral Pathol Med 1999;28(6):264-7.

7) Simpson RH, Clarke TJ, Sarsfield PT, Gluckman PG. Epithelialmyoepithelial carcinoma of salivary glands. J Clin Pathol 1991;44(5): 419-23.

8) Seethala RR, Barnes EL. Rare malignant and benign salivary gland epithelial tumors. Surg Pathol Clin 2011;4(4):1217-72.

9) Peters P, Repanos C, Earnshaw J, Stark P, Burmeister B, McGuire L, et al. Epithelial-myoepithelial carcinoma of the tongue base: A case for the case-report and review of the literature. Head Neck Oncol 2010;2:4.

10) Puri T, Singh K, Sharma DN, Khurana N. Epithelial-myoepithelial carcinoma of the base of tongue: Pathology and management. Indian J Cancer 2004;41(3):138-40.

11) Kumai Y, Ogata N, Yumoto E. Epithelial-myoepithelial carcinoma in the base of the tongue: A case report. Am J Otolaryngol 2006;27(1): 58-60.

12) Shah JP. Surgical approaches to the oral cavity primary and neck. Int J Radiat Oncol Biol Phys 2007;69(2 Suppl):S15-8.

13) Calabrese L, Pietrobon G, Fazio E, Abousiam M, Awny S, Bruschini $\mathrm{R}$, et al. Anatomically-based transoral surgical approach to earlystage oral tongue squamous cell carcinoma. Head Neck 2020;42(5): 1105-9.

14) Zhou S, Zhang C, Li D. Approaches of robot-assisted neck dissection for head and neck cancer: A review. Oral Surg Oral Med Oral Pathol Oral Radiol 2016;121(4):353-9.

15) Song CM, Ji YB, Sung ES, Kim DS, Koo HR, Tae K. Comparison of robotic versus conventional selective neck dissection and total thyroidectomy for papillary thyroid carcinoma. Otolaryngol Head Neck Surg 2016;154(6):1005-13. 